\title{
Aloe-Emodin-Mediated Photodynamic Therapy Attenuates Sepsis-Associated Toxins in Selected Gram-Positive Bacteria In Vitro
}

\author{
Woodvine Otieno, Chengcheng Liu*, and Yanhong Ji* \\ Department of Pathogenic Microbiology and Immunology, School of Basic Medical Sciences, Xi'an Jiaotong \\ University Health Science Center, 76 West Yanta Road, Xi'an 710061, P.R. China
}

\begin{abstract}
Sepsis is an acute inflammatory response that leads to life-threatening complications if not quickly and adequately treated. Cytolysin, hemolysin, and pneumolysin are toxins produced by grampositive bacteria and are responsible for resistance to antimicrobial drugs, cause virulence and lead to sepsis. This work assessed the effects of aloe-emodin (AE) and photodynamic therapy (PDT) on sepsis-associated gram-positive bacterial toxins. Standard and antibiotic-resistant Enterococcus faecalis, Staphylococcus aureus, and Streptococcus pneumonia bacterial strains were cultured in the dark with varying AE concentrations and later irradiated with $72 \mathrm{~J} / \mathrm{cm}^{-2}$ light. Colony and biofilm formation was determined. CCK-8, Griess reagent reaction, and ELISA assays were done on bacteriainfected RAW264.7 cells to determine the cell viability, NO, and IL-1 $\beta$ and IL-6 pro-inflammatory cytokines responses, respectively. Hemolysis and western blot assays were done to determine the effect of treatment on hemolysis activity and sepsis-associated toxins expressions. AE-mediated PDT reduced bacterial survival in a dose-dependent manner with $32 \mu \mathrm{g} / \mathrm{ml}$ of AE almost eliminating their survival. Cell proliferation, NO, IL-1 $\beta$, and IL- 6 cytokines production were also significantly downregulated. Further, the hemolytic activities and expressions of cytolysin, hemolysin, and pneumolysin were significantly reduced following AE-mediated PDT. In conclusion, combined use of AE and light (435 $\pm 10 \mathrm{~nm}$ ) inactivates MRSA, S. aureus (ATCC 29213), S. pneumoniae (ATCC 49619), MDR-S. pneumoniae, E. faecalis (ATCC 29212), and VRE (ATCC 51299) in an AE-dose dependent manner. AE and light are also effective in reducing biofilm formations, suppressing proinflammatory cytokines, hemolytic activities, and inhibiting the expressions of toxins that cause sepsis.
\end{abstract}

Keywords: Aloe-emodin, cytolysin, $\delta$-hemolysin, gram-positive bacteria, pneumolysin, sepsis

Received: May 20, 2021 Accepted: July 22, 2021

First published online: July 23,2021

${ }^{*}$ Corresponding authors C. Liu

Phone: +8618717324828

E-mail: liuchengc-

heng@xjtu.edu.cn

Y. Ji

Phone: +8615529691907

E-mail: jiyanhong@xjtu.edu.cn

pISSN 1017-7825

eISSN 1738-8872

Copyright(C) 2021 by

The Korean Society for

Microbiology and

Biotechnology

\section{Introduction}

Sepsis is an acute inflammatory response towards an infectious pathogen, accompanied by a complex chemical and cellular interaction cascade [1]. This immune response aims to eliminate the invasive microorganisms from the body. Despite the protective cellular mechanism, the acute response may damage tissues, causing lifethreatening problems if not quickly and adequately treated [2]. In recent years, sepsis incidence has been rising due to the growing elderly population, prolonged hospitalization, and increasingly aggressive medical procedures; thus, sepsis is causing a significant epidemiological and public health concern [3]. Nosocomial infectious diseases resulting from contaminated blood products, intravenous fluid, and medications have been reported [4]. The sepsis mortality rates vary from $12.8 \%$ (sepsis) and 20.7\% (severe sepsis) to $45.7 \%$ (septic shock) [5].

Gram-negative bacteria lipopolysaccharide (LPS) has been reported as the primary molecule accelerating sepsis by stimulating the release of endogenous mediators, thus causing the pathophysiological changes responsible for high mortality [6]. However, according to recent clinical reports, sepsis arising from gram-positive bacteria has been increasing and is responsible for $50 \%$ of septic shock or severe sepsis in intensive care units (ICUs) [7]. Methicillin-resistant Staphylococcus aureus (MRSA), Staphylococcus aureus, Streptococcus pneumoniae, Enterococcus faecalis, and vancomycin-resistant Enterococcus faecalis (VRE) are among these gram-positive bacteria responsible for sepsis.

In establishing infections, pathogens employ various virulence factors protecting them from the host's innate immune system and enabling them to invade the mucosal barriers, spread, and multiply in the neighboring organs. These gram-positive bacteria each express various exotoxins, consequently conferring antibiotic resistance. 
<smiles>O=C1c2cc(CO)cc(O)c2C(=O)c2cccc(O)c21</smiles>

Fig. 1. The chemical structure of aloe-emodin.

To counteract resistance to antimicrobials and to contain immune evasion by exotoxins, a search for alternative therapy is necessary.

A promising option is photodynamic therapy (PDT). The procedure involves combining appropriate light wavelengths and a photosensitizer (PS) dye sensitive to light. The irradiation generates reactive oxygen species (ROS), leading to the destruction of biomolecules and killing disease-causing bacterial cells. Compared to other ways of treatment, the advantages of PDT are outstanding. The PS mainly demonstrates minimal dark cytotoxicity and only turns highly cytotoxic on irradiation with light [8]. The treatment region size is dependent on the area of light irradiation, hence ensuring minimum harmful effect on the adjacent normal tissues. The technique is generally based on the transfer of energy from excited PSs to molecular oxygen to generate singlet oxygen $\left({ }^{1} \mathrm{O}_{2}\right)$, which instantly destroys bacterial biomolecules and initiates the death of cells.

Aloe-emodin (1,8-dihydroxy-3-(hydroxymethyl)anthraquinone) (Fig. 1) is a naturally occurring anthraquinone isolated from Aloe barbadensis Miller, and Rheum palmatum L. AE has been shown to have anti-cancer, antiinflammatory, antiviral, and antiparasitic effects [9]. Our previous report also demonstrated the anti-fungal activity of AE against drug-sensitive and drug-resistant Candida albicans [10]. Because of its ability to exhibit fluorescence and its maximum excitation wavelength of $430 \mathrm{~nm}, \mathrm{AE}$ is a suitable PS [11]. The maximum peak of absorption in the blue region also makes AE a promising PS for treatment of superficial infections [12]. However, the role of AE-mediated PDT on sepsis-related toxins remains unclear. This work assessed the AE-mediated PDT on Standard and antibiotic-resistant S. aureus (MRSA), S. pneumoniae, E. faecalis, and vancomycin-resistant E. faecalis (VRE) gram-positive bacteria.

\section{Materials and Methods}

Photosensitizer (PS) and Light

AE (Nanjing Jinzhu Biotechnology Co., China) was freshly prepared by dissolving in dimethyl sulfoxide (DMSO) (Sigma-Aldrich) to prepare working concentrations of 2, 4, 8, 16, and $32 \mu \mathrm{g} / \mathrm{ml}$ for various assays, as previously reported [13], after filtration using $0.22 \mu \mathrm{M}$ sterile filters. The AE absorption spectrum was recorded on a UV-Vis spectrophotometer (Agilent 8453, USA). A 50W xenon lamp (Ceaulight CELHXF300, China) was used for irradiation assays. White light with a $435 \pm 10 \mathrm{~nm}$ wavelength was determined by an optical filter (Ceaulight CEL UVIRCUT PD-145, China) and used for assays. The Xenon lamp emission spectrum was recorded on a fiber optic spectrometer (S3000, Seemantech, China). A power meter (Ceaulight CEL-NP2000, China) was used for adjustment of the power density of $0.08 \mathrm{~W} / \mathrm{cm}^{2}$ at the sample level. The distance between the optical filter and the bacterial samples was $10 \mathrm{~cm}$. To ensure constant cooling, an ice-cold water filter $(1 \mathrm{~cm}$ in width) was placed between the optical filter and the experimental samples. The samples were irradiated using 435 $\pm 10 \mathrm{~nm}$ white light for 10 minutes, with $72 \mathrm{~J} / \mathrm{cm}^{2}$ energy density.

\section{Bacterial Strains and Culture Conditions}

Standard S. aureus (ATCC 29213), S. pneumoniae (ATCC 49619), and E. faecalis (ATCC 29212) were all stored in our experimental laboratory. Clinical isolates of VRE (ATCC 51299), MRSA, and MDR S. pneumoniae (ATCC 49619) were obtained from the First Affiliated Hospital of Xi'an Jiaotong University, in Xi'an, China.

Standard and antibiotic-resistant S. aureus and E. faecalis strains were cultured on tryptone soy agar (TSA) (Qingdao Rishui Biotech) for $36 \mathrm{~h}$ at $37^{\circ} \mathrm{C}$. The resulting colonies were transferred to $10 \mathrm{ml}$ tryptone soy broth (TSB) (Qingdao Rishui Biotech, China) and grown to a log phase. The bacterial samples were then transferred into a $15 \mathrm{ml}$ tube, centrifuged for $15 \mathrm{~min}$ at 4,000 $\times \mathrm{g}$, and washed twice in sterilized PBS. The samples were then diluted to $1 \times 10^{7}$ colony forming units (CFU) per milliliter for subsequent assays. Antibiotic-resistant and standard S. pneumoniae bacterial strains were cultivated on blood agar plates (Beijing Kangqiao, China) for $36 \mathrm{~h}$ at $37^{\circ} \mathrm{C}$. The grown colonies were transferred to $10 \mathrm{ml}$ TSB supplemented in 5\% sheep blood. Later, the samples were incubated for $24 \mathrm{~h}$ at $37^{\circ} \mathrm{C}$ with shaking $(100 \mathrm{rpm})$ to a log phase of growth. Pellets were then harvested by centrifugation, washed two times in PBS, and resuspended to $1 \times 10^{7} \mathrm{CFU} / \mathrm{ml}$ density for subsequent assays.

\section{Bacterial PDI in Planktonic Culture}

Approximately $1 \times 10^{7} \mathrm{CFU} / \mathrm{ml}$ of bacteria in $2 \mathrm{ml}$ suspension were centrifuged for $15 \mathrm{~min}$ at 4,000 $\times g$ and resuspended in $2 \mathrm{ml} \mathrm{AE}$ with various concentrations $(0,2,4,8,16,32 \mu \mathrm{g} / \mathrm{ml})$. Samples were then incubated in the dark for $30 \mathrm{~min}$, then transferred to $35-\mathrm{mm}$ polystyrene culture dishes (Corning, USA). Irradiation was then done for $900 \mathrm{~s}$ using $435 \pm 10 \mathrm{~nm}$ light. Later, the pellets were spin for $10 \mathrm{~min}$ at $4,000 \mathrm{rpm}$, resuspended using sterilized PBS, and followed by a 10 -fold serial dilution. For standard and antibiotic-resistant $S$. aureus and E. faecalis strains, $20 \mu \mathrm{l}$ of dilution was spread in triplicate on TSA. Approximately $20 \mu \mathrm{l}$ of S. pneumoniae dilution was also spread on 
blood agar plates in triplicate and cultured for $48 \mathrm{~h}$ at $37^{\circ} \mathrm{C}$. The grown colonies were counted, and bacterial survival was determined using the following equation: $N_{P D I} / N_{0}$, where $N_{P D I}\left(\mathrm{CFU} / \mathrm{ml}\right.$ post-PDI) and $N_{0}$ (number of $\mathrm{CFU} / \mathrm{ml}$ without treatment).

\section{Biofilm Formation Assay}

Biofilm formation was assessed through the tissue culture plate method. Suspensions of bacteria were diluted in sterilized TSB to $1 \times 10^{6} \mathrm{CFU} / \mathrm{ml}$, and $200 \mu \mathrm{l}$ of the suspensions was inoculated into 96-well microplates and cultured for $24 \mathrm{~h}$ at $37^{\circ} \mathrm{C}$. After discarding the medium, the biofilms were washed in PBS two times. The biofilm fixation was done for $10 \mathrm{~min}$ using $95 \%$ ethanol and stained for $15 \mathrm{~min}$ with crystal violet $(0.1 \%(\mathrm{w} / \mathrm{v})(200 \mu \mathrm{l})$ at room temperature. The wells were then washed two times with PBS, dried for $2 \mathrm{~h}$ at $37^{\circ} \mathrm{C}$, and the formation of biofilm quantified through crystal violet stain solubilization in $30 \%(\mathrm{w} / \mathrm{v})$ glacial acetic acid (200 $\mu \mathrm{l})$ by shaking at $200 \mathrm{rpm}$ for $10 \mathrm{~min}$. The absorbance was finally determined at $492 \mathrm{~nm}$ (A492nm) using a microplate reader (Thermo Fisher 1510, Finland). A492nm > 0.240 was used to indicate the formation of biofilm.

\section{Bacterial Biofilms PDI}

Approximately $1 \times 10^{6} \mathrm{CFU} / \mathrm{ml}$ of the samples in $2 \mathrm{ml}$ suspension was inoculated into 24-well microplates containing sterilized glass coverslips and incubated for $24 \mathrm{~h}$ at $37^{\circ} \mathrm{C}$. After discarding the culture medium, biofilms adhered to coverslips were carefully washed twice with sterile PBS. The coverslips were then transferred to wells of another 24 -well microplate pre-filled with $2 \mathrm{ml}$ of AE at a concentration of $32 \mu \mathrm{g} / \mathrm{ml}$. The microplate was later incubated for $30 \mathrm{~min}$ at $37^{\circ} \mathrm{C}$ in the dark. The coverslips were then irradiated for $900 \mathrm{~s}$, gently washed twice, and transferred into the wells of a new 24-well microplate. The biofilms were later resuspended in sterilized PBS $(2 \mathrm{ml})$ and ultrasonicated in a sonicator (Hangzhou Front Ultrasonic FRQ-1002 T, China) for 10 min to dislodge the cells. Samples were then rapidly vortexed for 1 min using a vortex mixer (Haimen Qilinbeier QL-901, China). After a 10-fold serial dilution of the resulting suspensions in sterilized PBS, $20 \mu \mathrm{l}$ of each bacterial sample was plated in triplicate on TSA. After $24 \mathrm{~h}$ of incubation at $37^{\circ} \mathrm{C}$, the colonies were counted, and bacterial survival determined as described earlier.

\section{Cell Culture and Infection}

RAW264.7 cells, obtained from the institution biobank, were first cultivated in T-25 flasks in DMEM augmented with 10\% FBS to approximately $75 \%$ confluence. The cells were then seeded in 6-well plates and infected with various gram-positive bacteria; MRSA, S. aureus, E. faecalis, VRE, S. pneumoniae, and MDR S. pneumoniae for $1 \mathrm{~h}$ at 10 multiplicity of infection (MOI) [14]. For longer incubation time, the RAW264.7 cells were washed three times in PBS to eliminate unbound infectious bacteria and incubated further with a complete media supplemented with $16 \mu \mathrm{g} / \mathrm{ml}$ of vancomycin and $150 \mu \mathrm{g} / \mathrm{ml}$ of gentamicin to inactivate extracellular bacteria. After $12 \mathrm{~h}, \mathrm{AE}(32 \mu \mathrm{g} / \mathrm{ml})$ in complete fresh media was added to the cells and incubated for $30 \mathrm{~min}$. Later, cells were irradiated for $900 \mathrm{~s}$ and then incubated further for $12 \mathrm{~h}$ at $37^{\circ} \mathrm{C}$. For negative control, RAW264.7 cells uninfected with the study gram-positive bacteria were treated similarly to the experimental groups in every aspect.

\section{Cell Proliferation Assay}

RAW264.7 cell survival was determined as described previously [14]. Summarily, approximately $10^{6}$ cells/well were plated into 6-well plates and incubated for $24 \mathrm{~h}$ at $37^{\circ} \mathrm{C}$ and $5 \% \mathrm{CO}_{2}$ before infection. Triplicate wells of RAW264.7 cells were infected with MRSA, S. aureus, E. faecalis, VRE, S. pneumoniae, MDR S. pneumoniae at an MOI of 10 at $37^{\circ} \mathrm{C}$ and $5 \% \mathrm{CO}_{2}$ for $1 \mathrm{~h}$. The cells were later washed thrice in PBS and incubated further with DMEM augmented with $10 \% \mathrm{FBS}, 16 \mu \mathrm{g} / \mathrm{ml}$ vancomycin, and $150 \mu \mathrm{g} / \mathrm{ml}$ gentamicin. Cells were then incubated with $32 \mu \mathrm{g} / \mathrm{ml}$ of AE for $30 \mathrm{~min}$, irradiated $\left(72 \mathrm{~J} / \mathrm{cm}^{2}\right)$, and incubated for $48 \mathrm{~h}$ at $37^{\circ} \mathrm{C}$ in the dark. AE cytotoxicity was determined with Cell Counting Kit-8 (CCK-8) (Solarbio, China), following the manufacturer's guidelines. Summarily, CCK-8 solution $(10 \mu \mathrm{l})$ was added to every well, and the plates were subsequently incubated for $1 \mathrm{~h}$ at $37^{\circ} \mathrm{C}$. The absorbance was read in a microplate reader at $450 \mathrm{~nm}$. The rate of cell survival was calculated.

\section{Assessment of Nitric Oxide}

Nitric oxide (NO) generated by bacterial infected cells was measured using Griess reagent [15]. The bacteriainfected RAW264.7 cells were plated in 24 -well culture plates at $5 \times 10^{5}$ cells $/ \mathrm{ml}$, incubated at $37^{\circ} \mathrm{C}$ overnight, and treated with AE $(32 \mu \mathrm{g} / \mathrm{ml})$ for $30 \mathrm{~min}$. The cells were then irradiated for $900 \mathrm{~s}$ and incubated further for $24 \mathrm{~h}$. Later, cell supernatants $(50 \mu \mathrm{l})$ from every well were obtained and added in 96-well plates. Equal amounts of commercially acquired Griess reagent (Beyotime) were added as per the manufacturer's protocol. The plates were finally incubated at room temperature. Sodium nitrite reagent was used as the standard. The reaction was determined on a microplate reader (Thermo Fisher 1510) at $540 \mathrm{~nm}$ OD. Data were reported as the mean values from assays done in triplicate.

\section{Cytokine Analysis}

Approximately $5 \times 10^{5}$ cells/ml of RAW264.7 cells, infected with various study bacteria, were seeded in 24 -well culture plates and incubated at $37^{\circ} \mathrm{C}$ overnight. Proliferated cells were then treated with $32 \mu \mathrm{g} / \mathrm{ml}$ of AE, incubated for $30 \mathrm{~min}$, irradiated for $900 \mathrm{~s}$, and further incubated for $24 \mathrm{~h}$. The supernatant free of cells was collected to determine the concentration of IL- $1 \beta$ and IL- 6 through enzyme-linked immunosorbent assay (ELISA), following the manufacturer's guidelines (R\&D Systems, USA). The experiments were carried out in triplicates. 


\section{Hemolysis Assay}

The hemolysis studies were undertaken to assess the inhibitory effects of gram-positive bacteria on the hemolytic activity of cytolysin, $\delta$-hemolysin, and pneumolysin toxins after AE-mediated PDT. For this assay, the study was designed into four categories. Each sample of bacteria strain was divided into four groups as follows: group 1 was treated with neither light nor AE (P-L-), group 2 was to be treated with $72 \mathrm{~J} / \mathrm{cm}^{2}$ of light only (P-L+), group 3 with only $32 \mu \mathrm{g} / \mathrm{ml}$ of AE (P+L-), while group 4 was to be treated with both $\mathrm{AE}(32 \mu \mathrm{g} / \mathrm{ml})$ and light $(\mathrm{P}+\mathrm{L}+)$. According to the procedure, the supernatants of S. aureus (ATCC 29213) and MRSA, S. pneumoniae (ATCC 49619) and MDR S. pneumoniae (ATCC 49619), E. faecalis (ATCC 29212) and VRE (ATCC 51299) were first harvested by high-speed spinning at $10,000 \times g$ at $4^{\circ} \mathrm{C}$ for $5 \mathrm{~min}$. Later, $100 \mu \mathrm{l}$ of each bacterial supernatant was added to $1 \mathrm{ml}$ of sterile PBS buffer. These mixtures (for groups 3 and 4 ) were pre-incubated with $32 \mu \mathrm{g} / \mathrm{ml}$ of AE for $30 \mathrm{~min}$ at $37^{\circ} \mathrm{C}$ in the dark. Next, the samples were transferred to 6-well plates and irradiated for $900 \mathrm{~s}$ (except group 1) and collected back into $15 \mathrm{ml}$ tubes.

Later, $25 \mu \mathrm{l}\left(5 \times 10^{6}\right.$ cells/ml) of rabbit erythrocytes (R403-0100, Rockland Immunochemicals, Inc, USA) was added to each tube in all the groups and further incubated at $37^{\circ} \mathrm{C}$ for $30 \mathrm{~min}$. The tubes were centrifuged for $1 \mathrm{~min}$ at $6,000 \times g$ to remove the unlysed erythrocytes. Hemolytic activity was determined by assessing the supernatant's OD543 values. For the negative control, rabbit erythrocytes $(25 \mu \mathrm{l})$ were added into deionized water $(975 \mu \mathrm{l})$, and the bacterial supernatants were used as the $100 \%$ hemolysis control. The percentage hemolysis of light-only, AEonly, or AE-PDT samples was determined by comparison of the OD543 values of the test samples and control cultures.

\section{Western Blot Analysis}

For western blot assay, bacterial strains were cultivated in TSB while shaking at $200 \mathrm{rpm}$ at $37^{\circ} \mathrm{C}$ to an OD600 of 0.3 . Next, each bacterial culture was divided equally into four $50-\mathrm{ml}$ flasks (P-L-), (P-L+), $\mathrm{P}+\mathrm{L}-$ ) and $(\mathrm{P}+\mathrm{L}+$ ). The $\mathrm{P}+\mathrm{L}$ - and $\mathrm{P}+\mathrm{L}+$ were treated with $32 \mu \mathrm{g} / \mathrm{ml} \mathrm{AE}$ and cultured with shaking at $200 \mathrm{rpm}$ in a $37^{\circ} \mathrm{C}$ incubator for 30 min. Later, the cells $(\mathrm{P}-\mathrm{L}+),(\mathrm{P}+\mathrm{L}+)$ were irradiated for $900 \mathrm{~s}$. All the cells were then incubated again until OD600 of 2.5 was achieved. After this post-exponential phase of growth, the bacterial cultures were centrifuged for $5 \mathrm{~min}$ at $10,000 \times g$. The sample supernatants were heated in Laemmli buffer and loaded on a $12 \%$ sodium dodecyl sulfate-polyacrylamide (SDS). $\delta$-hemolysin was separated using $20 \%$ SDS. The proteins were then transferred to polyvinylidene fluoride (PVDF) membranes (Millipore, USA). The membrane blocking was done using $5 \%$ bovine serum albumin in sterile PBS at $37^{\circ} \mathrm{C}$ for $2 \mathrm{~h}$. Next, rabbit antibody against cytolysin (anti-PRF1; Cat\# SAB1406291-Sigma-Aldrich), $\delta$-hemolysin (Rabbit Anti-S. Aureus delta hemolysin-Cat \# SAB1305744; Sigma-Aldrich), and anti-mouse pneumolysin (IF11; sc-80500-Santa Cruz) were diluted to 1:1,000; and incubated with membranes at $4^{\circ} \mathrm{C}$ overnight. After three washes with PBS-tween, the membranes were incubated with relevant secondary antibodies $(1: 5,000)$ conjugated with horseradish peroxidase for $1 \mathrm{~h}$ at room temperature in the dark. The bands were detected using Immobilon Western Chemiluminescent HRP substrate (Millipore) and a Chemiluminescent Imaging System. Image J software was used to quantify the band formation after three independent experiments.

\section{Statistical Analysis}

The data were statistically analyzed using GraphPad Prism 7.0 software. The results were presented as the means \pm SD of values from three different experiments. The difference between the treated and control groups were analyzed using Student's $t$-test. Data comparison was done using one-way, or two-way ANOVA where appropriate, followed with a Bonferroni post-hoc test. $p<0.01$ was considered significant.

\section{Results}

$\mathrm{AE}$ demonstrated insignificant dark toxicity at the various concentrations assessed, as shown in Fig. 2. Irradiation without $\mathrm{AE}$ also indicated insignificant cytotoxicity (data not shown). AE and light combination demonstrated a bacterial inactivation effect in an AE-dose dependent manner, but only from 8-32 $\mu \mathrm{g} / \mathrm{ml}$. Use of $72 \mathrm{~J} /$ $\mathrm{cm}^{2}$ of light and 2 to $4 \mu \mathrm{g} / \mathrm{ml}$ of AE did not yield any noticeable bacterial survival reduction, while the use of 8,16 $\mu \mathrm{g} / \mathrm{ml} \mathrm{AE}$ resulted in bacterial survival reductions of 1.5 and $3.4 \log 10$ for E. faecalis (ATCC 29212) and $1.4 \log 10$ and $2.3 \log 10$ for VRE (ATCC 51299). Similarly, $8 \mu \mathrm{g} / \mathrm{ml}$ and $16 \mu \mathrm{g} / \mathrm{ml}$ AE yielded $1.3 \log 10$ and $3.3 \log 10$ survival reduction in S. aureus (ATCC 29213) and $1.3 \log 10$ and $2.6 \log 10$ reduction in the clinical MRSA strain, respectively. For the S. pneumoniae (ATCC 49619) standard strain, the treatments yielded a result of 1.3 and 3.2 $\log 10$ and $1.4 \log 10$ and $4.9 \log 10$ for the clinical MDR S. pneumonia isolate following the photodynamic treatment with 8 and $16 \mu \mathrm{g} / \mathrm{ml} \mathrm{AE}$, respectively. In all the experimental bacterial strains, the use of $32 \mu \mathrm{g} / \mathrm{ml}$ yielded approximately over $7 \log 10$ reduction in survival, indicating an effective killing.

Our observations on the biofilm indicated a significant formation. E. faecalis (ATCC 29212) and VRE (ATCC 51299 ) indicated an OD of 0.622 and 1.032, respectively, S. aureus (ATCC 29213) and MRSA yielded 2.466 and 2.825 (Fig. 3A). In S. pneumoniae and MDR S. pneumoniae, the observations were 2.378 and 2.568 OD, respectively. The observed OD values exceeded the A492 nm 0.240 limit, which indicated gram-positive biofilmgenerating bacteria. Further treatment of the produced biofilms with $32 \mu \mathrm{g} / \mathrm{ml}$ AE without irradiation using $72 \mathrm{~J} /$ $\mathrm{cm}^{2}$ light did not demonstrate a significant reduction in survival following biofilm treatment in the dark, as shown in Fig. 3B. However, the combination of AE and irradiation yielded $4.2 \log 10$ (E. faecalis), $3.6 \log 10$ (VRE), 4.3 $\log 10$ (S. aureus), $4.6 \log 10$ (MRSA), $4.1 \log 10$ (S. pneumoniae), and $4.3 \log 10$ (MDR S. pneumoniae), as shown in Fig. 3B. Further analysis showed that $\mathrm{AE}(2,4,8$, and $16 \mu \mathrm{g} / \mathrm{ml})$ and irradiation did not affect biofilm reduction. 

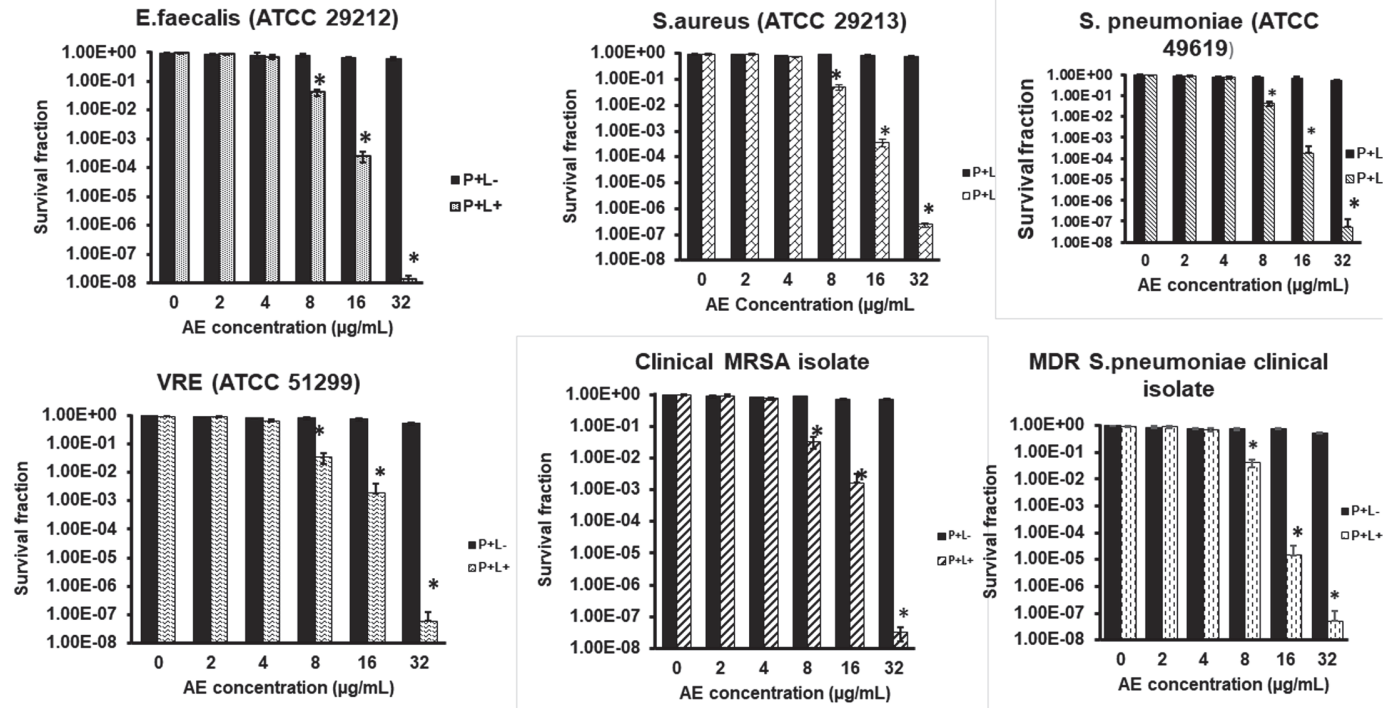

Fig. 2. Gram-positive bacteria survival fraction following treatments with various concentrations of AE. $\mathrm{P}+\mathrm{L}$ - indicates bacterial survival fraction following incubation without light therapy (dark toxicity). $\mathrm{P}+\mathrm{L}+$ indicates bacterial survival fraction post-irradiation with $72 \mathrm{~J} / \mathrm{cm}^{2}$ energy $(900 \mathrm{sec}) .{ }^{*}$ shows the level of significance at $p<0.05$ when compared to the untreated controls.

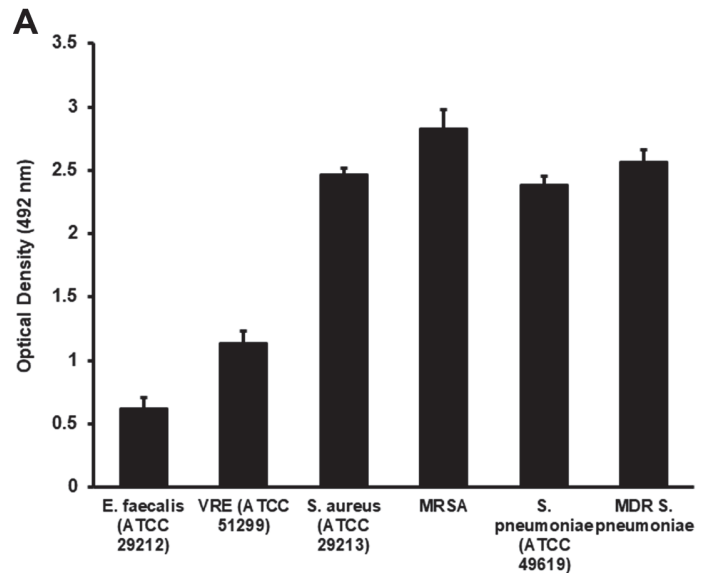

B

Fig. 3. (A) Gram-positive antimicrobial-resistant bacteria biofilm formation assays. (B) The survival fractions of the bacterial biofilms following treatments with $32 \mu \mathrm{g} / \mathrm{ml}$ of $\mathrm{AE}$ and irradiation. $\mathrm{P}+\mathrm{L}$ - indicates the survival fraction following irradiation with light for $900 \mathrm{sec}$ at a light density of $72 \mathrm{~J} / \mathrm{cm}^{2}$. ${ }^{*}$ Indicates a statistical significance $(p<0.05)$ when compared to the untreated group.

However, the use of $32 \mu \mathrm{g} / \mathrm{ml} \mathrm{AE}$ and light significantly regulated the biofilm formation in all the experimental bacterial strains, as shown in Fig. 4.

Cell viability studies result demonstrated significantly inhibited growth when the infected RAW264.7 cells were treated with a combination of $\mathrm{AE}$ ( of $32 \mu \mathrm{g} / \mathrm{ml}$ ) and light (900 s), compared to the controls (data not shown) or single treatments (Fig. 5A). NO is a well-described inflammatory response marker. Griess reagent reaction was used to determine the effect of treatment on NO production. Bacterial infections significantly stimulated the production of NO (data not shown), and the treatment with both AE and light significantly downregulated NO generation compared to the single treatment groups (Fig. 5B).

Further, we investigated whether AE-PDT affects pro-inflammatory cytokine production in bacteria-infected RAW264.7 cells. As demonstrated in Fig. 5C, AE-PDT significantly repressed IL-1 $\beta$ production compared to the bacteria-infected cells treated with either light or AE alone. Similarly, IL-6 production was significantly suppressed following the treatment of the cells with AE-PDT compared to the cells singly treated with light or AE (Fig. 5D).

Next, we investigated the potential AE-mediated photodynamic inactivation suppressor effects against cytolysin, d-hemolysin, and pneumolysin. The hemolytic activity of the toxins was assessed in post-bacterial 


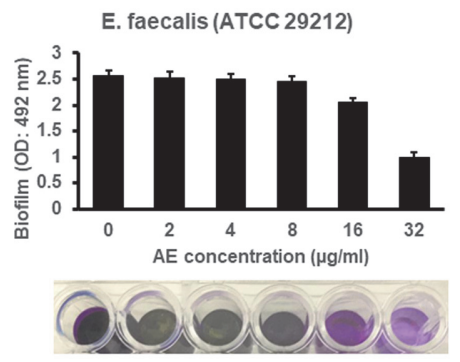

S. aureus
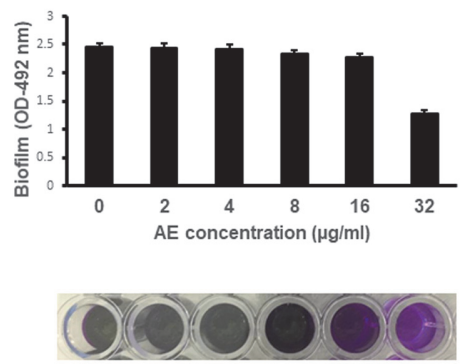

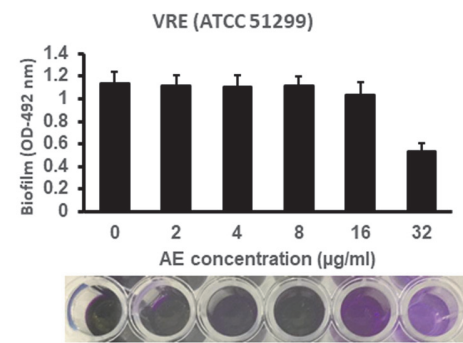

S. pneumoniae (ATCC 49619)
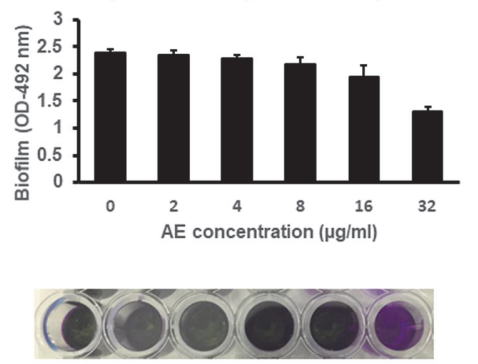

MRSA

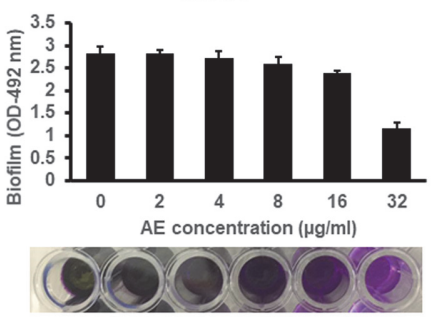

MDR S. pneumoniae
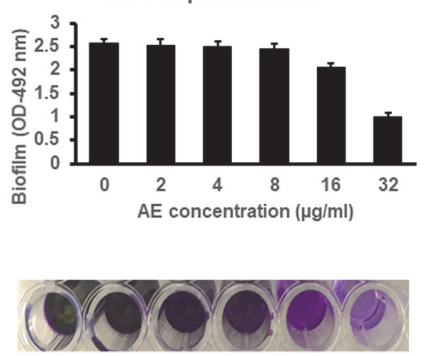

Fig. 4. Effects of AE-mediated PDT on gram-positive bacteria biofilm formations. Various stated experimental gram-positive antimicrobial-resistant bacteria were treated with $\mathrm{AE}(0,2,4,8,16$, or 32$) \mu \mathrm{g} / \mathrm{ml}$ and irradiated with $72 \mathrm{~J} / \mathrm{cm}^{2}$ light. Biofilm formation (OD 492) of various bacteria in 96-well culture plates was quantified after $24 \mathrm{~h}$.

A

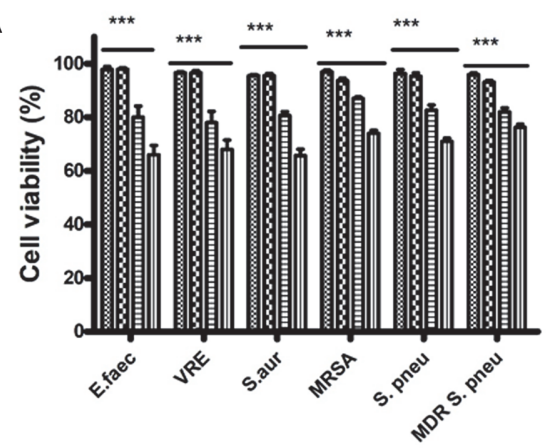

C

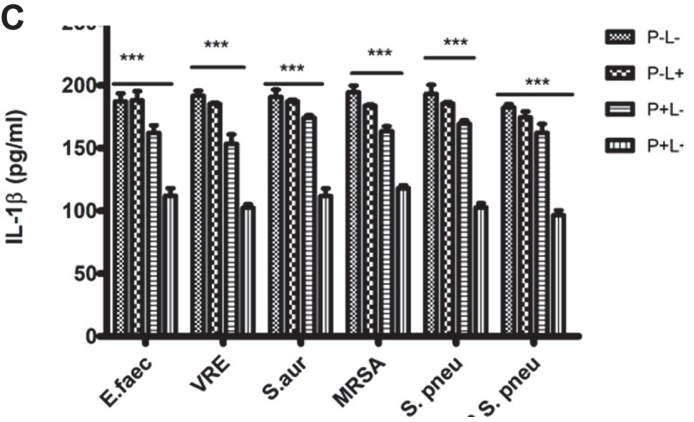

B P-L日 P+L孟 P+L+

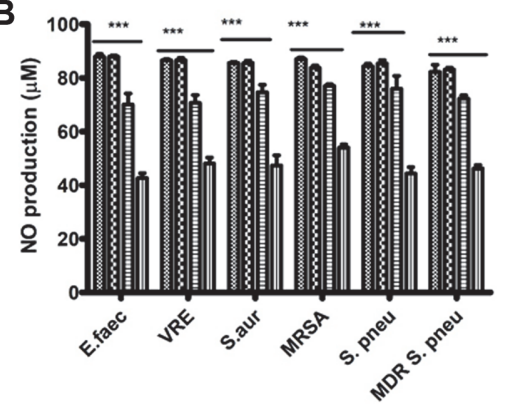

$\square$ P.L.

$\infty \mathrm{P}-\mathrm{L}+$

当 $P+L-$

血 P+L+

Fig. 5. A-D: Effects of AE-mediated PDT on viability and pro-inflammation factors production in bacterialinfected RAW264.7 cells. A: RAW264.7 cells infected with E. faecalis (ATCC 29212), VRE (ATCC 51299), S. aureus (ATCC 29213), MRSA, S. pneumoniae (ATCC 49619), and MDR S. pneumoniae (ATCC 49619), were plated in 96-wells plates and treated with either light $\left(72 \mathrm{~J} / \mathrm{cm}^{2}\right)(\mathrm{P}+\mathrm{L}-), \mathrm{AE}(32 \mu \mathrm{g} / \mathrm{ml})$ alone $(\mathrm{P}+\mathrm{L}-)$ or both $(\mathrm{P}+\mathrm{L}+)$ or no treatment $(\mathrm{P}-\mathrm{L}-)$ for $24 \mathrm{~h}$. A CCK8 assay determined the proliferation, and expression was done relative to control (DMSO). B: Bacteria-infected RAW264.7 cells were seeded in 24-wells culture plates overnight and treated with P-L-, $\mathrm{P}-\mathrm{L}+, \mathrm{P}+\mathrm{L}-$ or $\mathrm{P}+\mathrm{L}+$. NO levels in the culture media were determined using Griess reagent. C and D: Bacteria-infected RAW264.7 cells plated in 24-well culture plates overnight were pretreated with $\mathrm{P}-\mathrm{L}+, \mathrm{P}+\mathrm{L}-$, or $\mathrm{P}+\mathrm{L}+$ and cultured for $24 \mathrm{~h}$. The IL- $1 \beta$ and IL- 6 concentration was determined by ELISA. The experiments were conducted thrice in triplicates, and data were analyzed through two-way ANOVA. ${ }^{* *} \mathrm{p}<0.001$ compared to no treatment (P-L-). 
A

S. aureus (ATCC 29213)

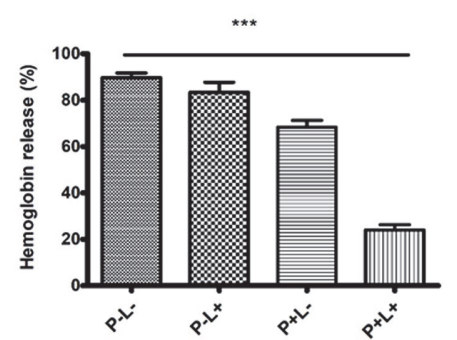

B

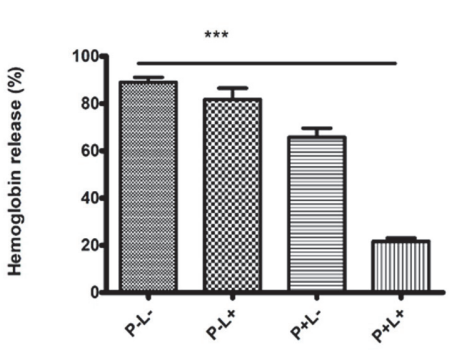

C

E. faecalis (ATCC 29212)

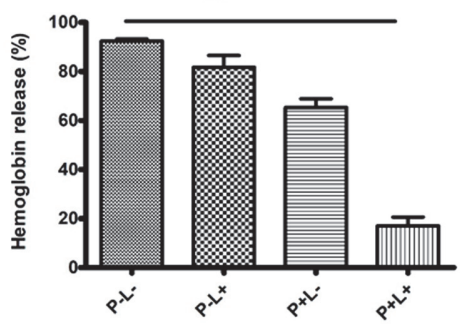

D

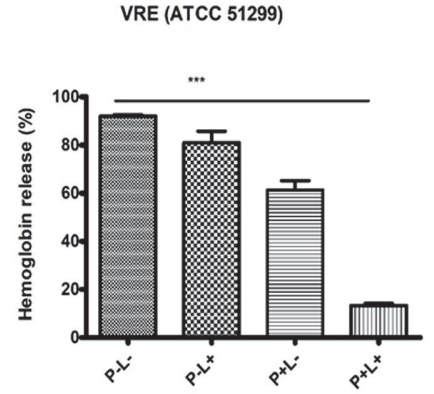

E

S. pneumoniae (ATCC 49619)

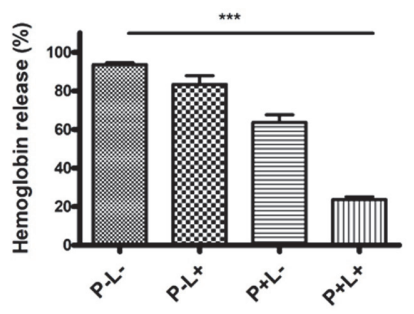

$\mathbf{F}$

MDR S. pneumoniae

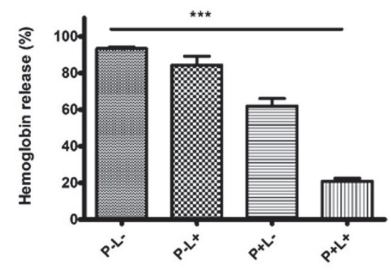

Fig. 6. A-F the indicated gram-positive bacteria were cultured with various treatments; negative control (P$\mathrm{L}-)$, AE alone $(32 \mu \mathrm{g} / \mathrm{ml})(\mathrm{P}+\mathrm{L}-)$, light alone $\left(72 \mathrm{~J} / \mathrm{cm}^{2}\right)(\mathrm{P}-\mathrm{L}+)$, AE and light $(\mathrm{P}+\mathrm{L}+)$. The supernatants were then used to assess the hemolytic activity. The observed hemolytic activity of culture bacteria supernatants co-cultured with various treatments were A: S. aureus (ATCC 29213) 89.67\% (P-L-) $83.33 \%$ (P-L+) $68.33 \%(\mathrm{P}+\mathrm{L}-$ ) and 24\% (P+L+) B: MRSA; 89\% (PL-) $81.67 \%(\mathrm{P}-\mathrm{L}+)$ 65.67\% (P+L-) and 21.67\% (P+L+) C: E. faecalis (ATCC 29212) 92.33\% (P-L-) , 81.67\% (P-L+) 65.33\% (P+L-) and $17 \%(\mathrm{P}+\mathrm{L}+$ ) D: VRE (ATCC 51299): 93\% (P-L-) 81\% (P-L+) 61.33\% (P+L-) and 13.3\% (P+L+) E: S. pneumoniae (ATCC 49619); 93.67\% (P-L-) 83.33\% (P-L+) 63.67\% (P+L-) and 23.66\% (P+L+). F: MDR-S pneumoniae: 93.33\% (P-L-) 84.33\% (P-L+) $62 \%(\mathrm{P}+\mathrm{L}-)$ and $21 \%(\mathrm{P}+\mathrm{L}+){ }^{* * *}$ Shows $p<0.0001$, compared with the untreated $(\mathrm{P}-\mathrm{L}-)$ group; two-tailed $t$-test.

treatments with light or $\mathrm{AE}$ alone or a combination of both. According to the observations, an insignificant reduction in the hemolytic activity was reported following treatment with light or AE alone. However, after treatment with $\mathrm{AE}$ and irradiation, the hemolytic activity was significantly decreased to $17 \%$ (E. faecalis), $13.3 \%$ (VRE), 24\% (S. aureus), 21.67\% (MRSA), 23.66\% (S. pneumoniae), and 21\% (MDR S. pneumoniae). In the control groups without AE or light treatment, $\delta$-hemolysin lysed $89.67 \%$ and $89 \%$ of rabbit erythrocytes in $S$. aureus and MRSA, respectively. Cytolysin toxin lysed $92.33 \%$ and $93 \%$ of the erythrocytes in E. faecalis and VRE, respectively, while pneumolysin lysed $93.67 \%$ and $93.33 \%$ erythrocytes in S. pneumoniae and MDR S. pneumoniae, respectively (Figs. 6A-6F).

Finally, we assessed whether AE-mediated photodynamic inactivation interferes with expression of cytolysin, $\delta$-hemolysin, and pneumolysin, which are the toxins responsible for the pathogenicity of the studied grampositive bacteria. According to the western blot results, a single treatment with either AE or light or lack of it, did not significantly interfere with PRF1 expression in both E. faecalis and VRE. However, the AE-mediated photodynamic inactivation significantly suppressed PRF1 expression in E. faecalis and VRE, as shown in Figs. 7A (i-ii) $(p>0.0001)$.

For the single treatments in $S$. aureus and MRSA, $\delta$-hemolysin expression was not significantly reduced, while AE-PDT drastically reduced its expression as shown in Figs. 7B (i) and 7B (ii), respectively $(p>0.0001)$. Similarly, single treatments or negative control studies did not demonstrate any significant reduction in pneumolysin expression in S. pneumoniae and MDR S. pneumoniae. Nevertheless, AE-mediated PDT significantly inhibited its expression, as depicted in Figs. 7C (i) and 7C (ii), respectively $(p>0.001)$.

\section{Discussion}

Persistent antimicrobials misuse has gradually led to their resistance, consequently leading to discontinuation after decades of use and the occurrence of various multidrug-resistant bacterial strains such as vancomycinresistant Enterococcus, MRSA, and MDR S. pneumoniae [16, 17]. Antibiotics use is directly associated with the survival of bacteria and results in resistant strains selection, finally to resistant flora. Therefore, there is a possibility that various antimicrobial drugs may finally cause resistance to drugs because of the excellent environmental adaptation capability of bacteria. Consequently, new and effective alternative treatment approaches are necessary to address the challenges of resistance.

According to multiple studies, targeting virulence factors is a better strategy that has demonstrated significant results $[18,19]$. Gram-positive bacteria generally induce inflammation by releasing cytolytic exotoxins, which are significant virulence factors that destroy the host's cell membrane and initiate various inflammatory processes 
A

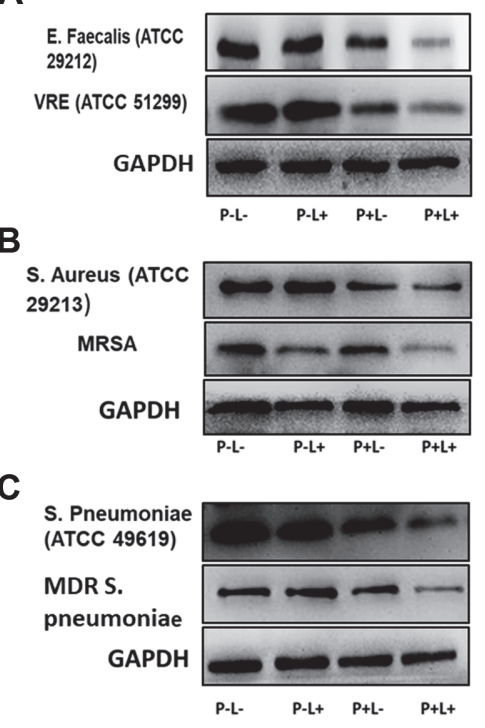

A (i)

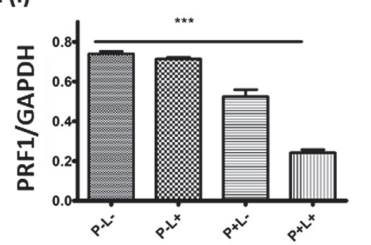

B (I)

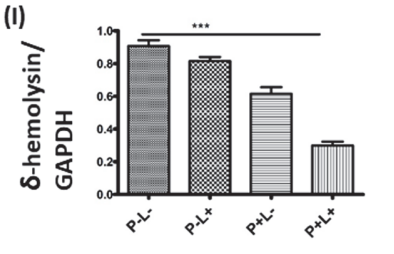

C (i)

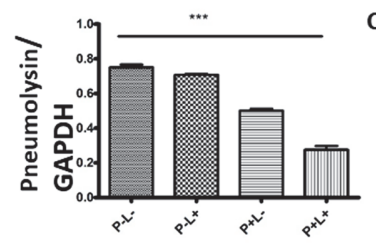

A (ii)
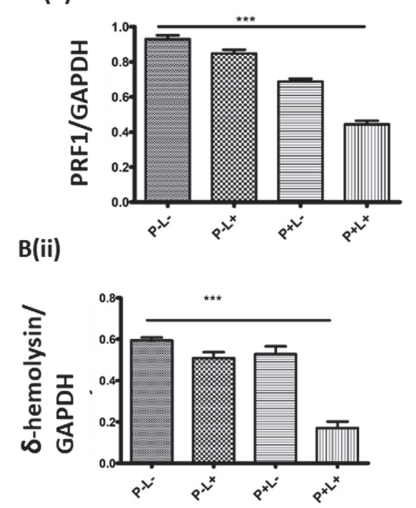

C (ii)

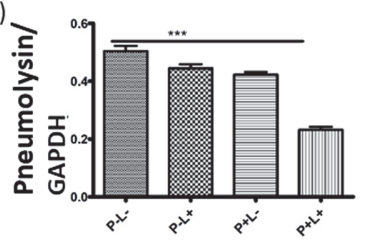

Fig. 7. Western blot assays determining the expressions of sepsis-associated exotoxins following bacterial treatments with light alone $\left(72 \mathrm{~J} / \mathrm{cm}^{2}\right)(\mathrm{P}-\mathrm{L}+), \mathrm{AE}(32 \mu \mathrm{g} / \mathrm{ml})$ alone $(\mathrm{P}+\mathrm{L}-)$ or AE combined with light $(\mathrm{P}+\mathrm{L}+)$ or no treatment (P-L-). A: Cytolysin toxin expression in Enterococcus spp. Following various treatments as stated. A (i): Bar graph representation of cytolysin toxin in E. faecalis (ATCC 29212) and A (ii): Bar graph representation of cytolysin toxin in VRE ATCC 51299). B: $\delta$-hemolysin toxin expression in Staphylococcus spp. following various treatments as stated. B (i): Bar graph representation of $\delta$-hemolysin in S. aureus (ATCC 29213). B (ii): Bar graph representation of $\delta$-hemolysin in MRSA. C: Pneumolysin toxin expression in Streptococcus spp. following various treatments as stated. C (i): Bar graph representation of pneumolysin in S. pneumoniae (ATCC 49619). C (ii): Bar graph representation of pneumolysin in MDR S. pneumoniae. GAPDH was used as the internal control. ${ }^{* * *}$ Indicates $p<0.0001$ compared with the untreated control group in a two-tailed Student's $t$-test.

[20]. PDT has been widely discussed as a promising tolerable and affordable alternative for treating bacterial infections [21]. However, investigations on its effects on gram-positive bacteria toxins do not exist.

The current study reports the photodynamic effects of AE coupled with light $(435 \pm 10 \mathrm{~nm})$ against Enterococcus, Staphylococcus, and streptococcal pathogens, which occur in an AE-dose-dependent manner. AE $(2-4 \mu \mathrm{g} / \mathrm{ml})$ and light irradiation did not inactivate the bacteria. However, 8,16 , and $32 \mu \mathrm{g} / \mathrm{ml}$ and irradiation all had reduced effects on the survival of bacteria in an AE-dose dependent manner with over $7 \log 10$ bacteria survival reduction in all the strains tested when $32 \mu \mathrm{g} / \mathrm{ml}$ AE was used.

Biofilms ensure microbes are protected from antibiotics and the host's immunity [22]. Biofilms of bacteria have been linked with infections such as periodontitis, cystic fibrosis, and nosocomial diseases on heart valves and catheters $[23,24]$. Our findings reported biofilm formation in all the bacteria under study. This observation is in agreement with a previous report that most isolates of Enterococcus, Staphylococcus, and Streptococcus bacteria can form biofilms and are therefore the reason for their resistance to at least one antibiotic [25].

Because of the role of biofilm formations in the successful establishment of infection, its destruction is an important way of curbing gram-positive bacterial infections. PDT has been shown to reduce the formation of biofilm in various studies [26]. We have also shown that PDT reduces the formation of biofilms following the use of Hypocrellin B and light [27]. This study further confirmed that AE-mediated PDT also reduced the formation of biofilms in gram-positive bacteria.

This study also reported an inhibited NO, IL-1 $\beta$, and IL-6 production in RAW264.7 cells, confirming the antiinflammatory potency of AE-mediated PDT. NO is an important pro-inflammatory cytokine for various infections, and its regulation is important for the control of sepsis [28]. Nitric oxide is generated in increased levels by iNOS proteins stimulated by pathogenic products, for instance, LPS. IL- $1 \beta$ is regarded as an early-produced pro-inflammatory cytokine that induces inflammation at the local and systemic levels [29]. IL-6 also plays a critical function in various inflammatory conditions, particularly in the acute-phase reactions [30].

Progressed gram-positive bacterial infections often lead to sepsis, whose hallmark is the presence of at least two systemic inflammation features, such as hypothermia or fever, leukopenia or leukocytosis, tachypnea, and tachycardia [31]. Enterococcal septicemia mediates an inflammatory severe immune response, which is a predisposing factor to secondary bacterial infections. The result is an increased septic shock incidence and multiple organ failure, eventually leading to increased mortality [32]. Staphylococcus spp. is associated with toxic shock syndrome (TSS), characterized by hypotension, organs failure, rash, fever, and myalgia [1]. Besides, S. pneumoniae has been linked with sepsis, referred to as invasive pneumococcal disease (IPD) [33]. Amongst various exotoxins produced by Enterococcus spp., cytolysin is a hemolytic and bactericidal toxin that causes 
multiple organ failure and death [34]. Staphylococcus spp., also produce $\delta$-hemolysin, which remains a wellcharacterized and prominent hemolytic exotoxin responsible for the pathogenesis of staphylococcal infections, killing various populations of host cells, such as the immune cells, and assisting in the spread of the pathogen within the host [35]. In S. pneumoniae, pneumolysin (PLY) is a hemolytic exotoxin essential in various pneumococcal disease steps. PLY cooperates with invasins, proteases, and adhesins for successful pathogenesis. PLY consequently contributes to the penetration of bacteria and inflammation, leading to the direct destruction of cells by a pore-forming cytolysis process and abetting the escape of bacteria through complement system blocking [36]. Indeed, our findings confirmed the hemolytic activities of cytolysin, $\delta$-hemolysin, and PLY, which were significantly reduced following AE-mediated PDT. The expressions of these exotoxins were also significantly reduced following AE-mediated PDT as was denoted by inhibited PRF1, $\delta$-hemolysin, and pneumolysin in the Enterococcus spp., Staphylococcus spp., and the Streptococcus spp., studied.

\section{Conclusion}

In conclusion, our findings confirmed that combined use of AE and light (435 $\pm 10 \mathrm{~nm})$ inactivates MRSA, S. aureus (ATCC 29213), S. pneumoniae (ATCC 49619), MDR-S. pneumoniae, E. faecalis (ATCC 29212), and VRE (ATCC 51299) in an AE-dose dependent manner. AE and light are also effective in reducing biofilm formations, suppressing NO, IL-1 $\beta$, IL-6, hemolytic activities, and inhibiting the expressions of toxins that cause sepsis.

\section{Conflict of Interest}

The authors have no financial conflicts of interest to declare.

\section{References}

1. Berg D, Gerlach H. 2018. Recent advances in understanding and managing sepsis. F1000Res. 7: F1000 Faculty Rev-1570.

2. Brady J, Horie S, Laffey JG. 2020. Role of the adaptive immune response in sepsis. Intensive Care Med. Exp. 8: 20.

3. Cabrera-Perez J, Condotta SA, Badovinac VP, Griffith TS. 2014. Impact of sepsis on CD4 T cell immunity. J. Leukoc. Biol. 96: 767777.

4. Al Achkar M, Rogers JS, Muszynski MJ. 2012. Pantoea species sepsis associated with sickle cell crisis in a pregnant woman with a history of pica. Am. J. Case Rep. 13: 26-28.

5. de Oliveira TH, Amorin AT, Rezende IS, Santos Barbosa M, Martins HB, Brito AK, et al. 2015. Sepsis induced by Staphylococcus aureus: participation of biomarkers in a murine model. Med. Sci. Monit. 21: 345-355.

6. Minasyan H. 2019. Sepsis: mechanisms of bacterial injury to the patient. Scand. J. Trauma Resusc. Emerg. Med. $27: 19$.

7. Martin GS. 2012. Sepsis, severe sepsis and septic shock: changes in incidence, pathogens and outcomes. Expert. Rev. Anti Infect. Ther. 10: 701-706.

8. Lv Z, Wei H, Li Q, Su X, Liu S, Zhang KY, et al. 2018. Achieving efficient photodynamic therapy under both normoxia and hypoxia using cyclometalated $\mathrm{Ru}(\mathrm{ii})$ photosensitizer through type I photochemical process. Chem. Sci. 9: 502-512.

9. Dong X, Fu J, Yin X, Cao S, Li X, Lin L, et al. 2016. Emodin: A review of its pharmacology, toxicity and pharmacokinetics. Phytother. Res. 30: 1207-1218.

10. Ma W, Liu C, Li J, Hao M, Ji Y, Zeng X. 2020. The effects of aloe emodin-mediated antimicrobial photodynamic therapy on drugsensitive and resistant Candida albicans. Photochem. Photobiol. Sci. 19: 485-494.

11. Chen Q, Li KT, Tian S, Yu TH, Yu LH, Lin HD, et al. 2018. Photodynamic therapy mediated by Aloe-Emodin inhibited angiogenesis and cell metastasis through activating MAPK signaling pathway on HUVECs. Technol. Cancer Res. Treat. 17: 1533033818785512.

12. Zang L, Zhao H, Ji X, Cao W, Zhang Z, Meng P. 2017. Photophysical properties, singlet oxygen generation efficiency and cytotoxic effects of aloe emodin as a blue light photosensitizer for photodynamic therapy in dermatological treatment. Photochem. Photobiol. Sci. 16: 1088-1094.

13. Jiang L, Yi T, Shen Z, Teng Z, Wang J. 2019. Aloe-emodin attenuates Staphylococcus aureus pathogenicity by interfering with the oligomerization of a-toxin. Front. Cell. Infect. Microbiol. 9: 157.

14. Zou J, Shankar NJI, immunity. 2014. Enterococcus faecalis infection activates phosphatidylinositol 3-kinase signaling to block apoptotic cell death in macrophages. Infect. Immun. 82: 5132-5142.

15. Cabral GRdA, Wang ZT, Sibley LD, DaMatta RA. 2018. Inhibition of nitric oxide production in activated macrophages caused by Toxoplasma gondii infection occurs by distinct mechanisms in different mouse macrophage cell lines. Front. Microbiol. 9: 1936.

16. Rasko DA, Sperandio V. 2010. Anti-virulence strategies to combat bacteria-mediated disease. Nat. Rev. Drug Discov. 9: 117-128.

17. Ventola CL. 2015. The antibiotic resistance crisis: part 1: causes and threats. P T 40: 277-283.

18. Qiu J, Niu X, Wang J, Xing Y, Leng B, Dong J, et al. 2012. Capsaicin protects mice from community-associated methicillin-resistant Staphylococcus aureus pneumonia. PLoS One 7: e33032.

19. Kong C, Neoh HM, Nathan S. 2016. Targeting Staphylococcus aureus toxins: A potential form of anti-virulence therapy. Toxins (Basel) 8: 72 .

20. Romp E, Arakandy V, Fischer J, Wolz C, Siegmund A, Löffler B, et al. 2020. Exotoxins from Staphylococcus aureus activate 5lipoxygenase and induce leukotriene biosynthesis. Cell. Mol. Life Sci. 77: 3841-3858.

21. Sharma B, Thakur V, Kaur G, Chaudhary GR. 2020. Efficient photodynamic therapy against Gram-positive and Gram-negative bacteria using rose bengal encapsulated in metallocatanionic vesicles in the presence of visible light. ACS Appl. Bio Mater. 12: 85158524.

22. Hall CW, Mah TF. 2017. Molecular mechanisms of biofilm-based antibiotic resistance and tolerance in pathogenic bacteria. FEMS Microbiol. Rev. 41: 276-301.

23. Delle-Bovi RJ, Smits A, Pylypiw HM. 2011. Rapid method for the determination of total monosaccharide in Enterobacter cloacae strains using fourier transform infrared spectroscopy. Am. J. Anal. Chem. 2: 212-216.

24. Khatoon Z, McTiernan CD, Suuronen EJ, Mah TF, Alarcon EI. 2018. Bacterial biofilm formation on implantable devices and approaches to its treatment and prevention. Heliyon 4: $\mathrm{e} 01067$.

25. Sobisch L-Y, Rogowski KM, Fuchs J, Schmieder W, Vaishampayan A, Oles P, et al. 2019. Biofilm forming antibiotic resistant grampositive pathogens isolated from surfaces on the international space station. Front. Microbiol. 10: 543.

26. Catão MHCdV, Batista ALA. 2020. In vitro evaluation of the antibacterial effect of photodynamic therapy with methylene blue. Pesqui. Bras. Odontopediatria Clin. Integr. 20. doi.org/10.1590/pboci.2020.073.

27. Otieno W, Liu C, Deng H, Li J, Zeng X, Ji Y. 2020. Hypocrellin B-mediated photodynamic inactivation of Gram-positive antibioticresistant bacteria: an in vitro study. Photobiomodul. Photomed. Laser Surg. 38: 36-42. 
28. Lambden S. 2019. Bench to bedside review: therapeutic modulation of nitric oxide in sepsis—an update. Intensive Care Med. Exp. 7: 64 .

29. Hullmann G, Azfer M, Hensley J, Bergese A, Lefer JJAJoB. 2015. Role of IL-1B in TLR4-mediated MCP-1expression: renal sepsis. Am. J. Biomed. 3: 22-31.

30. Franco DM, Arevalo-Rodriguez I, i Figuls MR, Oleas NGM, Nuvials X, Zamora JJCDoSR. 2019. Plasma interleukin-6 concentration for the diagnosis of sepsis in critically ill adults. Cocharne Database Syst. Rev. 4: CD011811.

31. Hotchkiss RS, Moldawer LL, Opal SM, Reinhart K, Turnbull IR, Vincent JL. 2016. Sepsis and septic shock. Nat. Rev. Dis. Primers 2: 16045 .

32. Huang XQ, Qiu JK, Wang CH, Pan L, Xu JK, Pan XH, et al. 2020. Sepsis secondary to multifocal Enterococcusfaecium infection: a case report. Medicine 99: e19811.

33. van der Poll T, Opal SM. 2009. Pathogenesis, treatment, and prevention of pneumococcal pneumonia. Lancet 374: 1543-1556.

34. Van Tyne D, Martin MJ, Gilmore MS. 2013. Structure, function, and biology of the Enterococcus faecalis cytolysin. Toxins (Basel) 5: 895-911.

35. Divyakolu S, Chikkala R, Ratnakar KS, Sritharan V. 2019. Hemolysins of Staphylococcus aureus_An update on their biology, role in pathogenesis and as targets for anti-virulence therapy. Adv. Infect. Dis. 9: 80-104.

36. Nishimoto AT, Rosch JW, Tuomanen EI. 2020. Pneumolysin: pathogenesis and therapeutic target. Front. Microbiol. $11: 1543$. 